\title{
Compact Electronically Reconfigurable WiMAX Band- Notched Ultra-wideband MIMO Antenna
}

\author{
Asim QUDDUS ${ }^{1}$, Rashid SALEEM ${ }^{2}$, Muhammad Farhan SHAFIQUE ${ }^{3}$, Sabih ur REHMAN ${ }^{4}$ \\ ${ }^{1}$ Dept. of Electrical Engineering, University of Engineering and Technology (UET), Taxila, 47050, Pakistan \\ ${ }^{2}$ Dept. of Telecommunication Engineering, University of Engineering and Technology (UET), Taxila, 47050, Pakistan \\ ${ }^{3}$ Centre for Advance Studies in Telecommunication, COMSATS Inst. of Information Technology (CIIT), Islamabad, Pakistan \\ ${ }^{4}$ School of Computing and Mathematics, Charles Sturt University, Australia
}

engrraqs@gmail.com

Submitted November 17, 2017 / Accepted July 17, 2018

\begin{abstract}
A low-profile electronically reconfigurable WiMAX band-notched dual port multiple-input multipleoutput (MIMO) antenna design for ultra-wideband application has been presented. The two symmetrical MIMO antenna elements proposed in this work exhibit a good impedance match $(V S W R \leq 2)$ over frequency band of 3 to $12 \mathrm{GHz}$, while offering high isolation. The decoupling structure is used to enhance the isolation level above $25 \mathrm{~dB}$ over the entire UWB spectrum. The reconfigurable band notch characteristic in MIMO design is achieved by inserting PIN diodes along the filtering $\Omega$-shaped slotted structure in main radiators. Notch appears for WiMAX $3.5 \mathrm{GHz}(3.2-3.8 \mathrm{GHz})$ frequency band by switching the $P I N$ diode to 'ON' state. The proposed antenna is fabricated and measured, the results suggest its appropriateness for UWB applications where WiMAX band notch characteristics may be desired on-demand.
\end{abstract}

\section{Keywords}

Band notch, isolation, multiple-input multiple-output (MIMO), PIN diodes, reconfigurable, ultra-wideband (UWB), WiMAX

\section{Introduction}

Wireless technologies have gained much research attention over the last few decades. The prime focus of efforts put in these technologies are related to resource optimization, cost cutting and achieving high data rates along with little interference to other existing wireless communication standards. A communication system with an absolute bandwidth of more than $500 \mathrm{MHz}$ is considered as an Ultra-Wide Band (UWB) system. The UWB spectrum from 3.1 to $10.6 \mathrm{GHz}$ offers bandwidth of $7.5 \mathrm{GHz}$ which is very attractive for future wireless technologies, mainly due to its license-free usage and possibility of achieving high data rate [1], [2]. By incorporation of MIMO technology in UWB systems, high data rates and improved channel capacities can be achieved. However, miniaturization is a significant challenge in UWB-MIMO antenna design. Due to unwanted mutual coupling caused by miniaturization, effectiveness of MIMO system is compromised. Therefore, an efficient decoupling structure is necessary in MIMO systems to provide high isolation between antenna elements without compromising the size. Numerous antennas have been reported in the existing literature, in which the decoupling/isolation structures are applied to reduce mutual coupling without affecting the compactness. The decoupling structure mainly enhances the isolation by reflecting and/or absorbing radiation from the radiators. Decoupling structure prevents the interference of the radiations of antenna elements in MIMO system. For isolation purpose slotted structures are placed between antenna elements. Frequency Selective Surface (FSS) based decoupling structures and Defected grounds are used in [5] to enhance the isolation between antenna elements. A decoupling structure is placed at the rear of the substrate to eliminate undesired mutual coupling between the antenna elements [7]. In [15] a long ground slot is introduced vertically on the T-shaped ground to provide better isolation between the two input ports.

Generally, different wireless standards, WiMAX being one of them, overlap the frequency spectra 3.1 to 10.6 GHz dedicated for UWB communication [2]. Therefore, it is highly likely that a UWB communication system will create distortion in other narrow-band systems working in this band or vice versa. The straightforward solution to this issue is to design an antenna having band notch characteristics. In this regard several band notch antennas have been reported in the existing literature. In one study reported in [8], a parasitic structure pair is etched in a ground plane to notch WLAN band. Integration of a slot resonator is presented in [9]. In [10], inverted parasitic strips for interference mitigation at $5.2 / 5.8 \mathrm{GHz}$ are reported. A combination of slotted and parasitic structures is proposed in [11]. Defected ground and notching structures in feed line is presented in [12-14]. However, band notch characteristics proposed in all these designs are permanent and for the sake of interference free communication, utili- 
zation of the whole UWB spectrum may not be possible even if there is no conflicting narrow band system working in the close proximity. Therefore, for the improvement in performance of an UWB system, antennas with reconfigurable structures exhibiting switchable band notch capability are highly desired [16-24]. In [21-24] the reconfigurability is not electronically controllable and for UWB and band notch operations one has to design two separate designs. Electronically reconfigurable antennas are preferred due to their multi-operability. They can utilize the whole UWB spectrum, and for interference mitigation, the antenna can behave like a band notch antenna within the same system when desired. Different types of microwave switches such as PIN diodes and RF MEMS, can be used for switching purpose in reconfigurable antenna structures [18]. In [19], optically controlled switches are used in antenna system to provide switchable band-notch functionality, which is used in cognitive radio systems. However, in [20], [25], PIN diodes connected on a microstrip slot antenna are used to achieve the purpose of reconfigurable band notching.

In this paper, a miniaturized reconfigurable band notch dual port MIMO antenna is proposed for UWB applications. Compact flower shaped symmetrical antenna elements are designed. The antenna exhibits a rectangular defected ground plane on the rear side of a substrate. The antenna system operates at a wide range, covering frequency band of 3 to $12 \mathrm{GHz}$. A slotted rectangular shaped structure is designed on the ground plane to enhance decoupling between antenna elements. This decoupling structure provides isolation of more than $25 \mathrm{~dB}$ over the entire UWB band, while keeping other $\mathrm{MIMO} /$ diversity parameters (ECC, TARC and CCL) in an acceptable range. Moreover, electronically reconfigurable band notch characteristic in the proposed design is achieved by inserting PIN diodes in inverted $\Omega$ shaped slots present in the main radiating elements. The antenna system provides switchable band notch capability for WiMAX (3.2-3.8 GHz) band. For design and optimization of the proposed antenna geometry, full wave electromagnetic simulations have been carried out in Ansys High Frequency Structural Simulator (HFSS) using Finite Element Method (FEM).

\section{Design and Configuration of MIMO Antenna}

\subsection{MIMO Antenna Element Structure}

The structure of the proposed antenna system is presented in Fig. 1. The proposed antenna system is simulated and fabricated on FR4 substrate with relative permittivity, loss tangent and thickness of 4.4, 0.018 and $0.8 \mathrm{~mm}$, respectively. The proposed MIMO antenna has a compact overall size of $14 \mathrm{~mm} \times 30 \mathrm{~mm}$. The upper layer comprises of two center fed flower shaped radiating elements, whereas, the rear side of the substrate contains the ground plane. The proposed radiating elements are symmetrical and
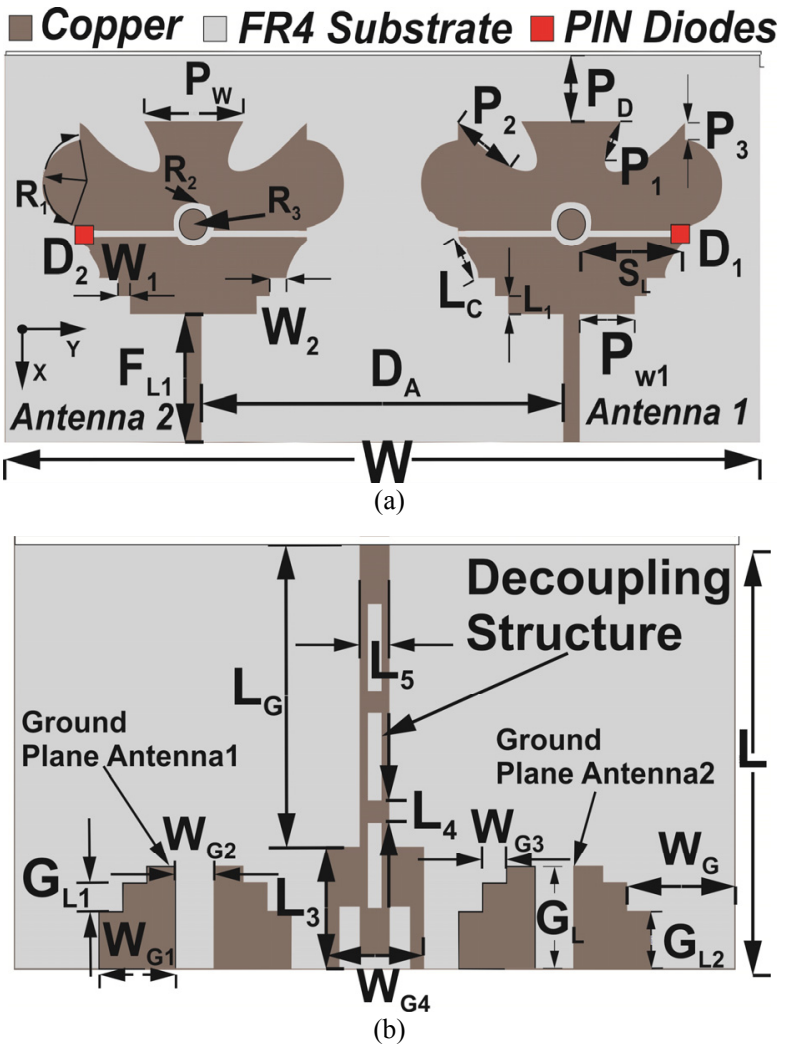

Fig. 1. Geometry of dual port antenna system: (a) Front view. (b) Rear view.

\begin{tabular}{|c|c|c|c|c|c|c|c|c|}
\hline Parameter & $\mathbf{L}$ & $\mathbf{W}$ & $\mathbf{L}_{\mathbf{1}}$ & $\mathbf{L}_{\mathbf{3}}$ & $\mathbf{L}_{\mathbf{4}}$ & $\mathbf{L}_{\mathbf{5}}$ & $\mathbf{L}_{\mathbf{G}}$ & $\mathbf{L}_{\mathbf{C}}$ \\
\hline Value $(\mathbf{m m})$ & 14 & 30 & 0.7 & 3.8 & 0.75 & 1.2 & 10.2 & 1.5 \\
\hline Parameter & $\mathbf{P}_{\mathbf{1}}$ & $\mathbf{P}_{\mathbf{2}}$ & $\mathbf{P}_{\mathbf{3}}$ & $\mathbf{P}_{\mathbf{W} 1}$ & $\mathbf{W}_{\mathbf{1}}$ & $\mathbf{W}_{\mathbf{2}}$ & $\mathbf{W}_{\mathbf{G}}$ & $\mathbf{W}_{\mathbf{G} 1}$ \\
\hline Value $(\mathbf{m m})$ & 0.7 & 2.6 & 0.6 & 2.2 & 0.5 & 0.7 & 4.5 & 3.2 \\
\hline Parameter & $\mathbf{G}_{\mathbf{L}}$ & $\mathbf{G}_{\mathbf{L} 1}$ & $\mathbf{D}_{\mathbf{A}}$ & $\mathbf{R}_{\mathbf{1}}$ & $\mathbf{R}_{\mathbf{2}}$ & $\mathbf{R}_{\mathbf{3}}$ & $\mathbf{F}_{\mathbf{L} 1}$ & $\mathbf{S}_{\mathbf{L}}$ \\
\hline Value $(\mathbf{m m})$ & 3.3 & 0.8 & 14.4 & 1.5 & 0.8 & 0.4 & 4.7 & 3.4 \\
\hline Parameter & $\mathbf{P}_{\mathbf{W}}$ & $\mathbf{P}_{\mathbf{D}}$ & $\mathbf{W}_{\mathbf{G} \mathbf{2}}$ & $\mathbf{W}_{\mathbf{G} 3}$ & $\mathbf{G}_{\mathbf{L} 2}$ & $\mathbf{W}_{\mathbf{G} 4}$ & - & - \\
\hline Value $(\mathbf{m m})$ & 4 & 2.1 & 1.6 & 1 & 1.8 & 4 & - & - \\
\hline
\end{tabular}

Tab. 1. Optimized values of proposed antenna.

are placed in side-by-side configuration in y-dimension. Partial grounding technique is used for ultra-wideband matching. Each antenna element is fed independently by a rectangular transmission line of $50 \Omega$. The feed line has width of $1.6 \mathrm{~mm}$ while the length is $F_{\mathrm{L} 1}$. The feed lines are $14.4 \mathrm{~mm}$ apart and placed $7.2 \mathrm{~mm}$ from the edges of the substrate. The partial ground plane is a notched rectangular strip of width $W_{\mathrm{G} 2}$. The antenna system operates at a wide frequency band of 3 to $12 \mathrm{GHz}$ except at the desired WiMAX notch frequency. The detailed parameters of antenna structure are listed in Tab. 1.

\subsection{MIMO Antenna Decoupling Structure}

The effect of decoupling structure on the mutual coupling $\left(S_{21}\right)$ is analyzed. To achieve high isolation between antenna elements, decoupling structure is added on the rear side of the substrate. The design of the decoupling structure for UWB-MIMO antenna is shown in Fig. 1(b). The 
decoupling structure consists of a defected rectangular stub line. The decoupling structure is placed between ground planes to isolate antenna elements that are placed in sideby-side arrangement. The decoupling structure effectively improves the isolation above $25 \mathrm{~dB}$. Table 1 shows the detailed parameters of the decoupling structure.

\subsection{Design of Reconfigurable Band Notch Structure}

The reconfigurable band notching in UWB-MIMO antenna is achieved by using PIN diodes. The effective length of the notching structure is required to filter out the desired frequency band. Notching at the desired frequency bands can be obtained using (1). At the notching frequency the structure works as a quarter wave resonator. $\Omega$ shaped slot is created in the main radiator of each antenna element.

$$
f_{\mathrm{r}}=\frac{C}{L_{\text {Total }} \sqrt{\varepsilon_{\text {effective }}}}
$$

where $L_{\text {Total }}=2 S_{\mathrm{L}}+2 \pi R_{2}$ and $C$ is the constant of electromagnetic wave velocity. The slot provides band notch characteristics at WiMAX 3.5 GHz. The current around the edges of slots reverses its direction causing anti-resonance at the desired notched frequency band. Moreover, to achieve the reconfigurable band notch functionality in UWB-MIMO antenna, PIN diode is added to the slot of each radiator, as shown in Fig. 1(a). The purpose of the PIN diode is to switch the UWB-MIMO antenna between ultra-wideband operation and WiMAX band notch functionality. The PIN diode $\mathrm{D}_{1}$ as shown in Fig. 1(a) controls the Antenna 1 band notching. Similarly, $\mathrm{D}_{2}$ PIN diode controls the band notching functionality of Antenna 2.

The reconfigurable characteristics of the proposed UWB-MIMO antenna have two operations as described below:

- Case I: When the diode is reverse biased or PIN diode is in its 'OFF State' the antenna does not offer notching; thus, the radiation is transmitted/received on the complete UWB without band rejection behavior.

- Case II: When the diode is forward biased or the PIN diode is in its 'ON State', the antenna introduces notch thus removing the interference caused by WiMAX.

The PIN diode is first modeled in HFSSTM using lumped elements according to the equivalent model for Case I and Case II, as shown in Figs. 2(a) and (b). During selection of PIN diode, the forward resistance and reverse bias capacitance are the two important parameters. SMP 1320-079 LF PIN diodes have been used for switching purpose. The diode has low reverse bias (zero volts) capacitance of $0.3 \mathrm{pF}$ at above $10 \mathrm{MHz}$ frequencies and very low resistance of $0.9 \mathrm{ohms}$ at $10 \mathrm{~mA}$, during forward bias operation. The equivalent model clearly shows the resistive behavior during forward biasing and capacitive effect when the diode is reverse biased. The circuitry of biasing network is also shown in Fig. 2(c). The current density ( $J$-surf) plots at $3.5 \mathrm{GHz}$ with diodes switching (ON/OFF) are shown in Figs. 3 and 4 to establish the effectiveness of band stop behavior. In this case Antenna element 1 is biased and Antenna element 2 is terminated with a matched load. It can be seen in Case II that due to the phase reversal of surface current at the notched frequency band, the current concentration is high near the filtering structure, which causes anti-resonance.

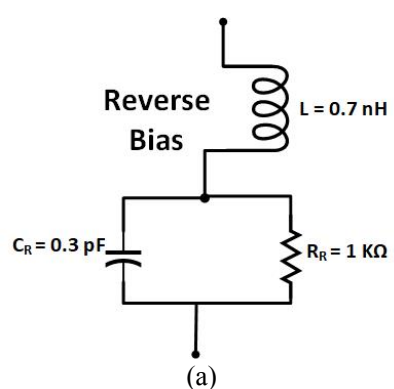

(a)

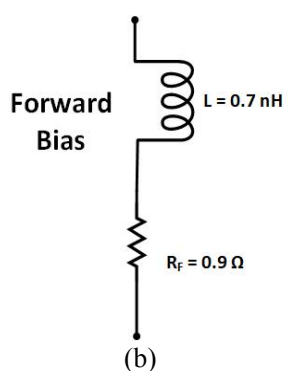

(b)

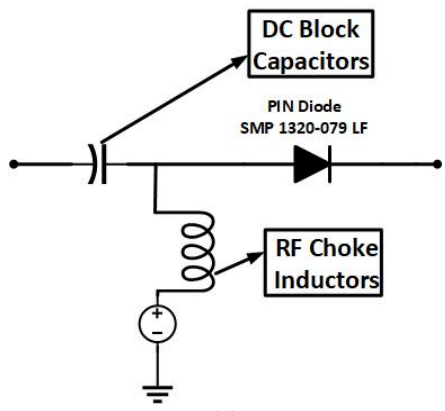

(c)

Fig. 2. Equivalent circuit model of PIN diodes: (a) Case I, (b) Case II, (c) biasing network

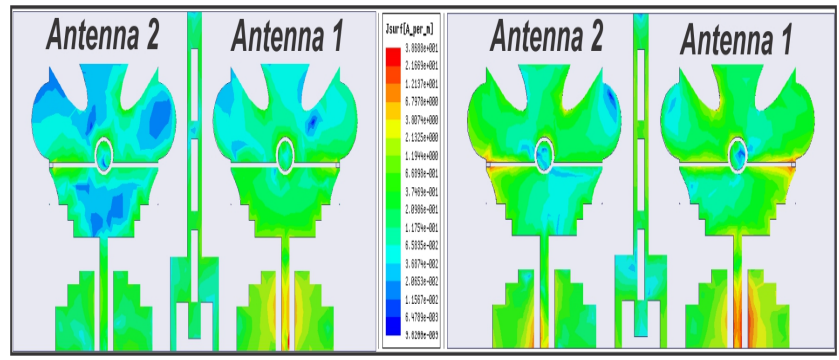

(a)

(b)

Fig. 3. Surface current density $J$-surf at $3.5 \mathrm{GHz}$ : (a) Case I. (b) Case II.

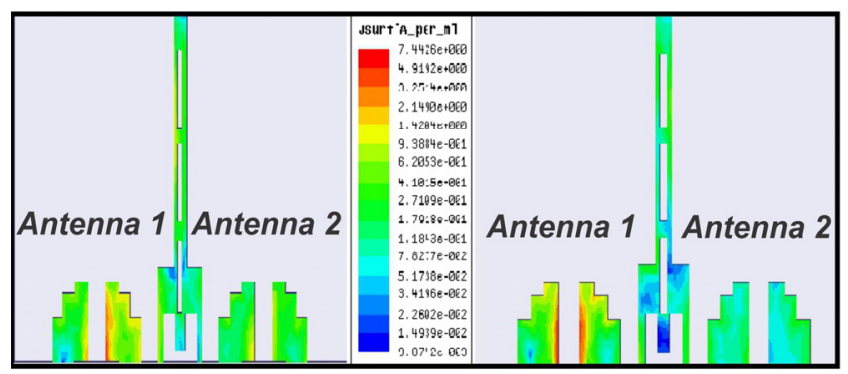

(a) (b)

Fig. 4. Surface current density $J$-surf on the ground plane at 3.5 GHz: (a) Case I. (b) Case II. 


\section{Results and Discussions}

\subsection{Impedance Matching}

The proposed design is fabricated on low cost FR4 laminate, the prototype is shown in Figs. 5(a) and (b). Agilent N5242A PNA-X network analyzer is used to carry out the measurements. As the antenna elements are identical, impedance matching is similar for each element. The simulated as well as measured results are presented in Fig. 6. The result shows that antenna elements are well matched over the entire band spectrum of 3 to $12 \mathrm{GHz}$ for Case I (diodes switched 'OFF'). However, for Case II (diodes switched 'ON') the proposed UWB-MIMO antenna provides WiMAX $(3.2-3.8 \mathrm{GHz})$ band notching. To determine the range of the notched band, a parametric analysis is done by varying radius $R_{2}$ of $\Omega$-shaped slot. The

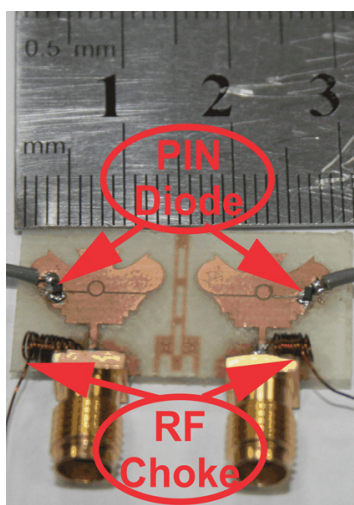

(a)

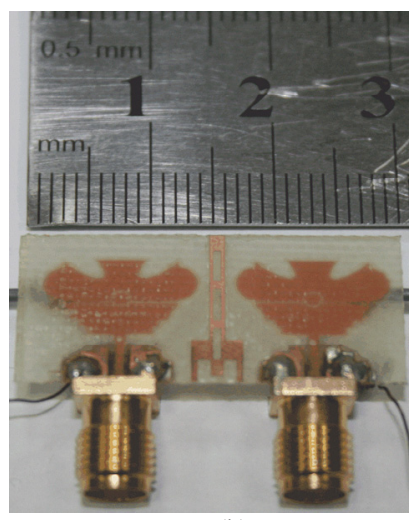

(b)
Fig. 5. Fabricated design: (a) Front view. (b) Rear view.
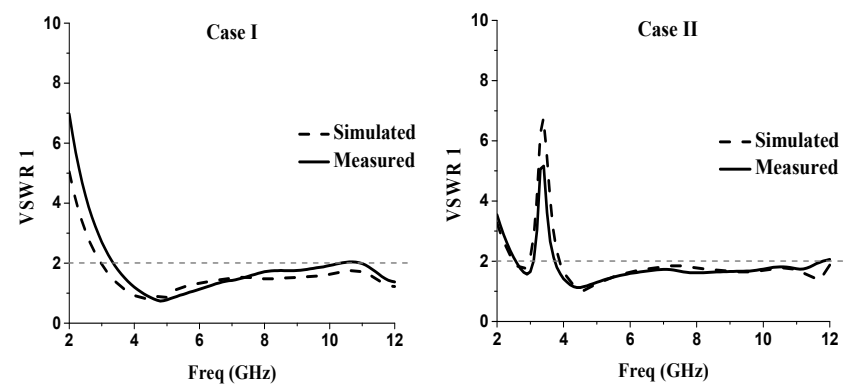

Fig. 6. Simulated and measured impedance matching of the prototype.

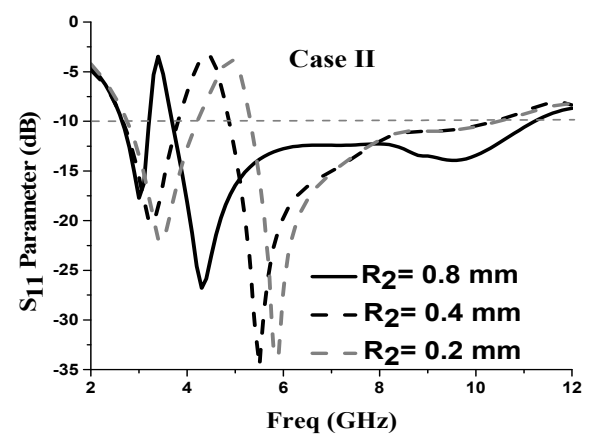

Fig. 7. Parametric analysis of notching structure. resulting effect on the reflection coefficient is analyzed and the results are shown in Fig. 7 for Case II.

The DC block inline SMA module has been installed with VNA so no onboard DC block capacitor is installed. However, the RF choke is added to both elements. Since the ground plane is electrically small so ferrite beads have been added to the measurement cables to reject the reverse current propagating on the outer side of the test cables.

\subsection{Isolation}

The decoupling structure comprising of a vertical strip along with rectangular slots in the middle has been added to the ground plane of the proposed antenna system in order to achieve the desired improved isolation. Although the coupling between the two antenna elements at low frequencies is below $-15 \mathrm{~dB}$ without the decoupling structure, it is acceptable for MIMO operations [2, 6, 15, $16,23]$. However, the incorporation of the decoupling structure further reduces the coupling between antenna elements by $10 \mathrm{~dB}$ for most of the operating band and is well below $-20 \mathrm{~dB}$ for lower frequencies in our desired band [1], [17]. This enhanced isolation ensures minimal correlation among the signals coming from different paths, thus improving the diversity gain further when a suitable combining scheme is employed. The effect of decoupling structure on mutual coupling of antenna elements, for both Case I and II, can be observed clearly from Fig. 8. The overall simulated as well as measured isolation with decoupling structure is better than $25 \mathrm{~dB}$. Separate ground planes for MIMO antennas is not a new concept as reported in [7], [17]. The main reason behind good isolation performance of the proposed antennas is non-conventional shape of antenna elements and the incorporated decoupling structure. These antennas with separate ground

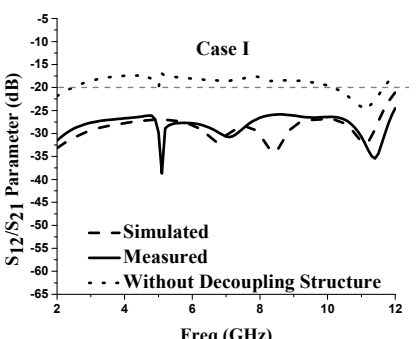

(a)

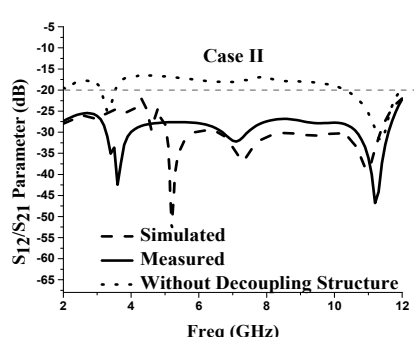

(b)
Fig. 8. Mutual coupling of the prototype.

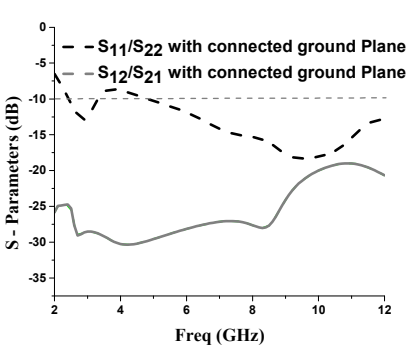

(a)

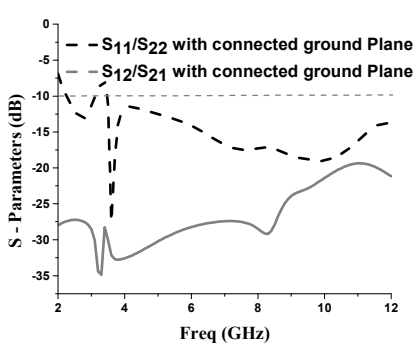

(b)
Fig. 9. S parameters analysis: (a) Case I. (b) Case II. 
planes also offer better impedance matching over operating frequency band. The effect of the common ground plan for the proposed antenna can be analyzed in Fig. 9. The figure shows that the connected ground plane mainly affects the impedance matching of the antenna. The isolation with the connected ground plane is also less than $20 \mathrm{~dB}$ for most of the UWB band, which indicates that the isolation enhancement in the proposed MIMO antenna is mainly because of the decoupling structure between the antenna elements as shown in Fig. 8.

\subsection{Radiation Characteristics}

The simulated and measured radiation patterns in $\mathrm{E}$ and $\mathrm{H}$ plane of the proposed MIMO antenna (Case I and Case II), observed at $3.5,7,9.5$ and $12 \mathrm{GHz}$ are plotted in Fig. 10. It can be noted that the simulated and measured radiation patterns are well within the acceptable range.

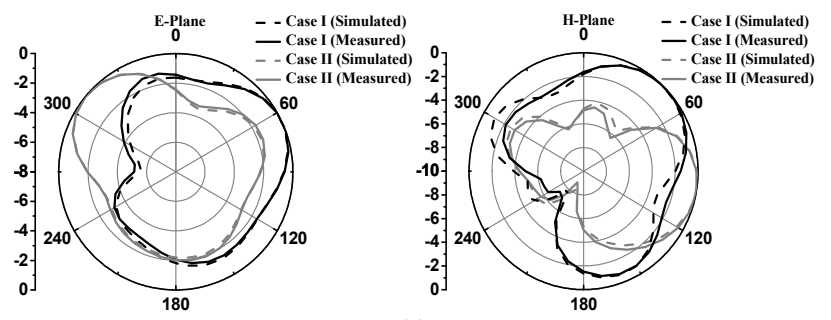

(a)

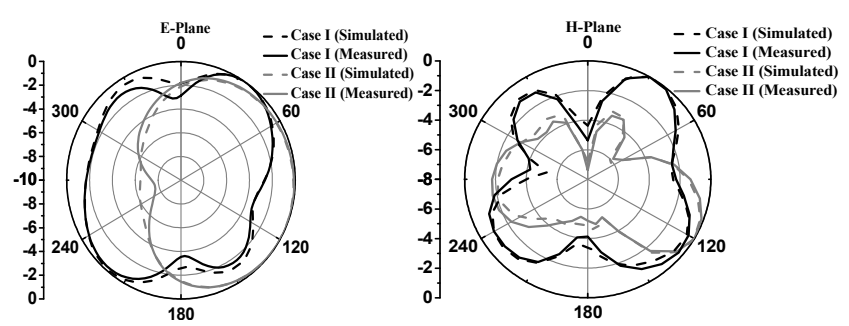

(b)

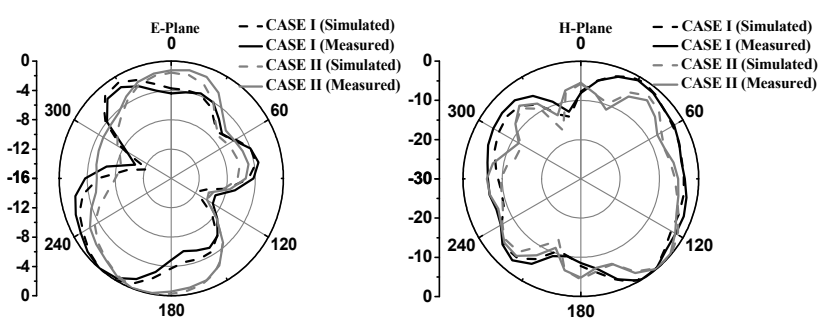

(c)

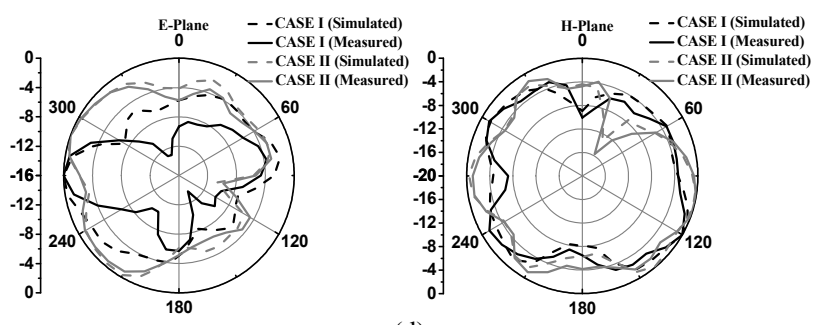

(d)

Fig. 10. Radiation plots: (a) $3.5 \mathrm{GHz}$, (b) $7 \mathrm{GHz}$, (c) $9.5 \mathrm{GHz}$, (d) $12 \mathrm{GHz}$.

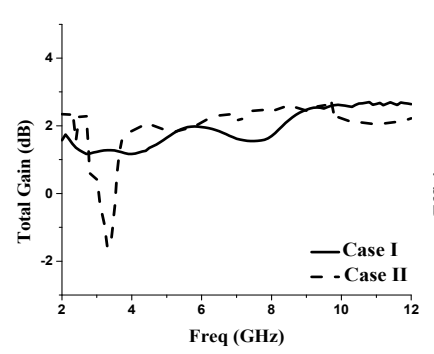

(a)

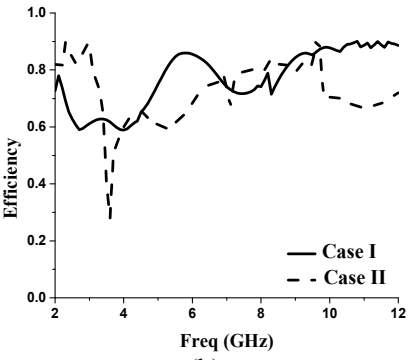

(b)
Fig. 11. (a) Gain of the proposed antenna. (b) Efficiency of the proposed antenna.

\subsection{Gain and Efficiency}

The proposed MIMO antenna system shows band notch characteristics. Therefore, in order to have a good analysis of the notched WiMAX band, gain and efficiency characteristics of the proposed prototype have been compared for both cases. In general, it is desirable to have lower gain and efficiency at the notching frequencies. The simulated gain and efficiency results are shown in Fig. 11. It clearly depicts that the proposed antenna offers a good gain and efficiency response over the whole UWB band except for the notched WiMAX band.

\subsection{Diversity Performance of Antenna}

The diversity performance of the proposed MIMO antenna system is investigated by analyzing different parameters like Envelop Correlation Coefficient (ECC), Total Active Reflection Coefficient (TARC) and Channel Capacity Loss (CCL). ECC is an important diversity parameter of MIMO system. For an isotropic rich scattering environment ECC can be estimated from S-parameters using (2), the expression is derived in [28]. By using this approach, we can analyze the explicit influence of mutual coupling and input match, without considering the radiation pattern of the antenna system [3, 7, 16, 17, 26, 29]. ECC value below $-3 \mathrm{~dB}$ is desired for optimum MIMO operations [26]. As shown in Fig. 12(a), (b), the results are well within an acceptable range for both cases (I, II).

$$
\rho_{\mathrm{e}}=\frac{\left|S_{i i}^{*} S_{i j}+S_{j i}^{*} S_{j j}\right|^{2}}{\left(1-\left|S_{i i}\right|^{2}+\left|S_{j i}\right|^{2}\right)\left(1-\left|S_{j j}\right|^{2}+\left|S_{i j}\right|^{2}\right)} .
$$

TARC and CCL are other important diversity parameters. TARC represents the ratio between square roots of the total reflected power and the total incident power, as shown in (3), whereas CCL elaborates the loss of capacity induced due to the correlation between MIMO channels. CCL is calculated from S parameters using (4) where $\psi^{\mathrm{R}}$ is a $2 \times 2$ correlation matrix.

$$
T A R C=\frac{\sqrt{\sum_{i=1}^{N}\left|S_{\text {reflected }}\right|^{2}}}{\sqrt{\sum_{i=1}^{N}\left|S_{\text {incident }}\right|^{2}}},
$$




$$
C C L=-\log _{2} \operatorname{det}\left(\psi^{\mathrm{R}}\right) .
$$

For optimum MIMO operation it is desired to have TARC $<0 \mathrm{~dB}$ and $C C L<0.5 \mathrm{bits} / \mathrm{sec} / \mathrm{Hz}$ in the operating band [22]. Figure 12(c) and (d) show that the values of TARC for Case I and Case II are well within the allowable limits. In Figs. 12(e) and (f), CCL parameter is calculated for antenna elements placed in side-by-side arrangement. Results suggest that CCL value is well below $0.5 \mathrm{bits} / \mathrm{sec} / \mathrm{Hz}$ for Case I. In Case II the CCL value at WiMAX (3.2-3.8 GHz) band is above $0.5 \mathrm{bits} / \mathrm{sec} / \mathrm{Hz}$, because of the anti-resonant effect of band notching structure. Group delay for UWB MIMO antenna elements for transmit and receive antenna is also analyzed and shown in Figs. 12 (g) and (h).

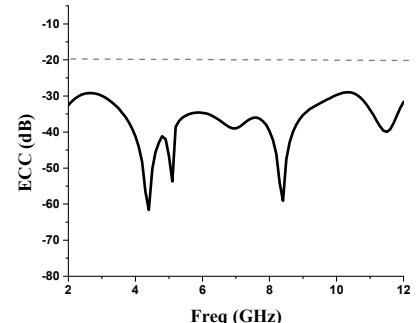

(a)

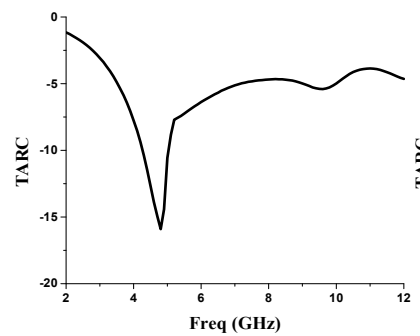

(c)

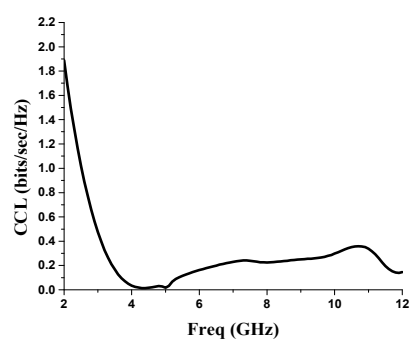

(e)

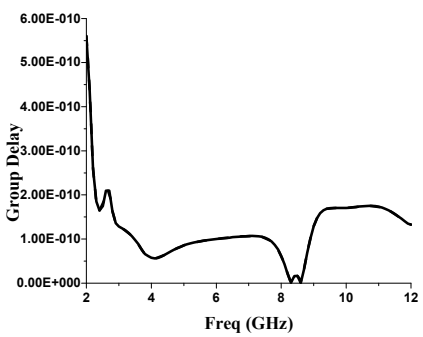

(g)

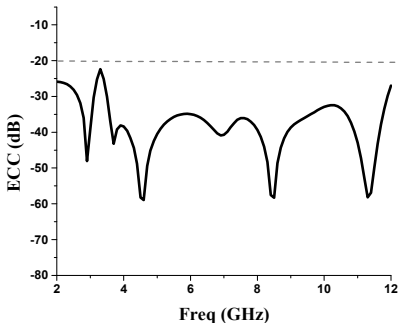

(b)

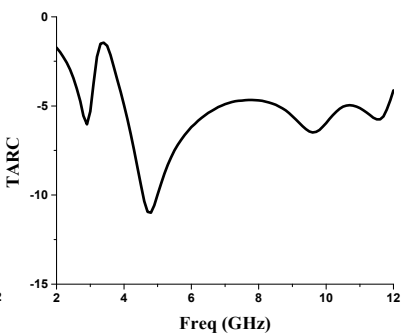

(d)

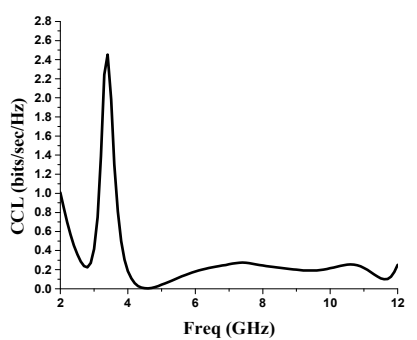

(f)

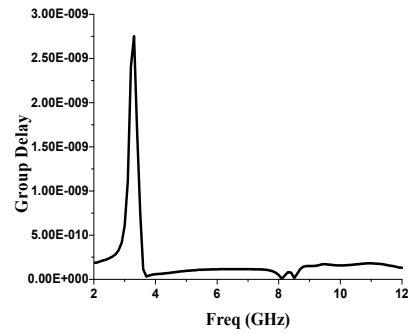

(h)
Fig. 12. Measured MIMO performance parameters: (a) ECC for Case I. (b) ECC for Case II. (c) TARC for Case I. (d) TARC for Case II. (e) CCL for Case I. (f) CCL for Case II. (g) Group delay for Case I. (h) Group delay for Case II.

\begin{tabular}{|c|c|c|c|c|}
\hline Ref. & $\begin{array}{c}\text { Isolation } \\
\text { (dB) }\end{array}$ & $\begin{array}{c}\text { No. of } \\
\text { Ports }\end{array}$ & $\begin{array}{c}\text { Antenna } \\
\text { dimensions }\left(\mathbf{m m}^{\mathbf{3}} \mathbf{)}\right.\end{array}$ & $\begin{array}{c}\text { Reconfigur } \\
\text {-ability }\end{array}$ \\
\hline$[\mathbf{1}]$ & $>20$ & 2 & $35 \times 35 \times 1$ & No \\
\hline$[\mathbf{1 5}]$ & $>15$ & 2 & $22 \times 36 \times 1.6$ & No \\
\hline$[\mathbf{1 7}]$ & $>20$ & 2 & $23 \times 39.8 \times 1.524$ & Yes \\
\hline$[\mathbf{2 7}]$ & $>15$ & 2 & $50 \times 82 \times 1.6$ & No \\
\hline $\begin{array}{c}\text { Proposed } \\
\text { antenna }\end{array}$ & $>25$ & 2 & $14 \times 30 \times 0.8$ & Yes \\
\hline
\end{tabular}

Tab. 2. Comparison of the proposed MIMO antenna with designs reported in existing literature.

The proposed MIMO antenna elements are compact as compared to various antennas reported in literature previously [4-7]. The comparison of the proposed antenna characteristics with other MIMO antenna designs $[1,15$, 17, 27] is listed in Tab. 2.

\section{Conclusion}

A low profile dual port reconfigurable MIMO antenna system is proposed in this research work for ultrawideband applications. The antenna system consists of two symmetrical flower shaped elements. Slotted rectangular shaped decoupling structure is introduced on the ground to enhance isolation. The proposed MIMO antenna operates over a frequency band of 3-12 GHz, while exhibiting isolation $\left(\mathrm{S}_{21}\right)$ of more than $25 \mathrm{~dB}$. Moreover, the reconfigurable band notch characteristics for WiMAX $(3.2 \mathrm{GHz}$ to $3.8 \mathrm{GHz}$ ) band have also been achieved by installing PIN diodes along $\Omega$ shaped filtering structure in the main radiating elements. Diversity parameters like ECC, CCL and TARC are also within the allowed limits. The simulated and measured results are in good agreement which confirms its appropriateness for reconfigurable UWB-MIMO operation.

\section{References}

[1] ZHU, J., LI, S., FENG, B., et al. Compact dual polarized UWB quasi-self-complementary $\mathrm{MIMO} /$ diversity antenna with bandrejection capability. IEEE Antennas and Wireless Propagation Letters, 2016, vol. 15, p. 905-908. DOI: 10.1109/LAWP. 2015.2479622

[2] ZHANG, J. Y., ZHANG, F., TIAN, W. P., et al. ACS-fed UWBMIMO antenna with shared radiator. Electronics Letters, 2015, vol. 51, p. 1301-1302. DOI: 10.1049/el.2015.1327

[3] HUANG, H., LIU, Y., GONG, S. Uniplanar differentially driven UWB polarisation diversity antenna with band-notched characteristics. Electronics Letters, 2015, vol. 51, p. 206-207. DOI: $10.1049 / \mathrm{el} .2014 .3626$

[4] MAO, C. X., CHU, Q. X. Compact coradiator UWB-MIMO antenna with dual polarization. IEEE Transactions on Antennas and Propagation, 2014, vol. 62, no. 9, p. 4474-4480. DOI: 10.1109/ TAP.2014.2333066

[5] SHABBIR, T., SALEEM, R., AKRAM, A., et al. UWB-MIMO quadruple with FSS-inspired decoupling structures and defected grounds. Applied Computational Electromagnetics Society Journal, 2015, vol. 20, no. 2, p. 184-190. ISSN: 1054-4887 
[6] KHAN, M. S., CAPOBIANCO, A. D., ASIF, S., et al. Compact $4 \times 4$ UWB-MIMO antenna with WLAN band rejected operation. Electronics Letters, 2015, vol. 51, p. 1048-1050. DOI: 10.1049/ el.2015.1252

[7] JAFRI, S. I., SALEEM, R., SHAFIQUE, M. F., et al. Compact reconfigurable multiple-input-multiple-output antenna for ultrawideband applications. IET Microwaves, Antennas \& Propagation, 2016, vol. 10, p. 413-419. DOI: 10.1049/iet-map.2015.0181

[8] OJAROUDI, N., GHADIMI, N. UWB small slot antenna with WLAN frequency band-stop function. Electronics Letters, 2013, vol. 49, no. 21, p. 1317-1318. DOI: 10.1049/el.2013.2577

[9] DISSANAYAKE, T., ESSELlE, K. P. Prediction of the notch frequency of slot loaded printed UWB antennas. IEEE Transactions on Antennas and Propagation, 2007, vol. 55, no. 11, p. 3320-3325. DOI: 10.1109/TAP.2007.908792

[10] HUANG, C. Y., HUANG, S. A., YANG, C. F. Band-notched ultra-wideband circular slot antenna with inverted C-shaped parasitic strip. Electronics Letters, 2008, vol. 44, no. 15, p. 891-892. DOI: $10.1049 / \mathrm{el}: 20081143$

[11] OJAROUDI, N., OJAROUDI, M., GHADIMI, N. Dual bandnotched small monopole antenna with novel W-shaped conductor backed-plane and novel T-shaped slot for UWB applications. IET Microwaves, Antennas \& Propagation, 2013, vol. 7, no. 1, p. 8-14. DOI: 10.1049/iet-map.2012.0180

[12] CAI, Y. Z., YANG, H. C., CAI, L. Y. Wideband monopole antenna with three band-notched characteristics. IEEE Antennas and Wireless Propagation Letters, 2014, vol. 13, p. 607-610. DOI: 10.1109/LAWP.2014.2313178

[13] KARIMIAN, R., ORAIZI, H., FAKHTE, S. Design of a compact ultra-wide-band monopole antenna with band rejection characteristics. IET Microwaves, Antennas \& Propagation, 2014 vol. 8, no. 8, p. 604-610. DOI: 10.1049/iet-map.2013.0085

[14] LIU, J. J., ESSELLE, K. P., HAY, S. G., et al. Planar ultra-wideband antenna with five notched stop bands. Electronics Letters, 2013, vol. 49, no. 9, p. 579-580. DOI: 10.1049/el.2012.4123

[15] LIU, L., CHEUNG, S. W., YUK, T. I. Compact MIMO antenna for portable UWB applications with band-notched characteristic. IEEE Transactions on Antennas and Propagation, 2015, vol. 63, no. 5, p. 1917-1924. DOI: 10.1109/TAP.2015.2406892

[16] SOLTANI, S., LOTFI, P., MURCH, R. D. A port and frequency reconfigurable MIMO slot antenna for WLAN applications. IEEE Transactions on Antennas and Propagation, 2016, vol. 64, no. 4, p. 1209-1217. DOI: 10.1109/TAP.2016.2522470

[17] KHAN, M. S., CAPOBIANCO, A. D., NAQVI, A., et al. Compact planar UWB MIMO antenna with on-demand WLAN rejection. Electronics Letters, 2015, vol. 51, no. 13, p. 963-964. DOI: $10.1049 / \mathrm{el} .2015 .1056$

[18] BADAMCHI, B., NOURINIA, J., GHOBADI, C., et al. Design of compact reconfigurable ultra-wideband slot antenna with switchable single/dual band notch functions. IET Microwaves, Antennas \& Propagation, 2014, vol. 8, no. 8, p. 541-548. DOI: 10.1049/iet-map.2013.0311

[19] ZHENG, S. H., LIU, X., TENTZERIS, M. M. Optically controlled reconfigurable band-notched UWB antenna for cognitive radio systems. Electronics Letters, 2014, vol. 50, no. 21, p. 1502-1504. DOI: $10.1049 / \mathrm{el} .2014 .2226$

[20] TASOUJI, N., NOURINIA, J., GHOBADI, C., et al. A novel printed UWB slot antenna with reconfigurable band-notch characteristics. IEEE Antennas and Wireless Propagation Letters, 2013, vol. 12, p. 922-925. DOI: 10.1109/ LAWP.2013.2273452

[21] LI, Y. S., LI, W. X., YE, Q. B. A reconfigurable triple-notch-band antenna integrated with defected microstrip structure band-stop filter for ultra-wideband cognitive radio applications. International
Journal of Antennas and Propagation, 2013, vol. 2013, p. 1-13. DOI: $10.1155 / 2013 / 472645$

[22] LI, Y. S., LI, W. X., YE, Q. B. Miniaturization of asymmetric coplanar strip-fed staircase UWB Antenna with reconfigurable notch band. Microwave and Optical Technology Letters, 2013, vol. 55, no. 7, p. 1467-1470. DOI: 10.1002/ mop.27634

[23] LI, Y. S., LI, W. X., YE, Q. B. A reconfigurable wide slot antenna integrated with SIRs for UWB/ multi-band communication applications. Microwave and Optical Technology Letters, 2013, vol. 55, no. 1, p. 52-55. DOI: 10.1002/mop.27253

[24] LI, Y. S., LI, W. X., YU, W. H. A switchable UWB slot antenna using SIS-HSIR and SIS-SIR for multi-mode wireless communications applications. Applied Computational Electromagnetics Society Journal, 2012, vol. 27, no. 4, p. 340-351. ISSN: 1054-4887

[25] KALTEH, A. A., DADASHZADEH, G. R., NASERMOGHADASI, M., et al. Ultra-wideband circular slot antenna with reconfigurable notch band function. IET Microwaves, Antennas \& Propagation, 2012, vol. 6, no. 1, p. 108-112. DOI: 10.1049/iet-map.2011.0125

[26] BILAL, M., KHALIL, K., SALEEM, R., et al. An interdigital FSS based dual channel UWB-MIMO antenna array for system-inpackage applications. Applied Computational Electromagnetics Society Journal, 2017, vol. 32, no. 3, p. 203-208. ISSN: $1054-4887$

[27] TOKTAS, A. G-shaped band-notched ultra-wideband MIMO antenna system for mobile terminals. IET Microwaves, Antennas \& Propagation, 2016, vol. 11, no. 5, p. 718-725. DOI: 10.1049/ietmap.2016.0820

[28] BLANCH, S., ROMEU, J., CORBELLA, I., Exact representation of antenna system diversity performance from input parameter description. Electronics Letters, 2003, vol. 39, p. 705-707. DOI: 10.1049/el:20030495

[29] CHANDEL, R., GAUTAM, A. K., RAMBABU, K. Tapered fed compact UWB MIMO-diversity antenna with dual band-notched characteristics. IEEE Transactions on Antennas and Propagation, 2018, vol 66, no. 4, p. 1677-1684 DOI 10.1109/TAP.2018.2803134

\section{About the Authors ...}

Asim QUDDUS received his BS degree in Electronics Engineering in 2012 from the International Islamic University, Islamabad, Pakistan. In 2012 he was awarded graduate scholarship by the University of Engineering and Technology (UET), Taxila, Pakistan. He received MS degree in Electrical Engineering from UET Taxila in 2014. Currently he is a PhD Scholar and working as Research Associate in MAP (Microwaves, Antennas and Propagation) research group at the Department of Telecommunication Engineering, UET Taxila. His research interests include UWBMIMO antennas, 3-D antennas and RF/microwave periodic structures including EBG and Frequency Selective Surfaces.

Rashid SALEEM received BS in Electronic Engineering from Ghulam Ishaq Khan Institute of Engineering Sciences and Technology, Pakistan, in 1999. He pursued a career in the telecommunication industry for several years while continuing education. He received M.S. from UET Taxila through Center for Advanced Studies in Engineering, 
Pakistan, in 2006 and $\mathrm{PhD}$ from the University of Manchester, United Kingdom in 2011. He worked on antennas, channel modeling and interference aspects of Ultra Wideband systems during his $\mathrm{PhD}$ and was also member of a team designing and testing arrays for the Square Kilometer Array project. Currently, he is working as an Assistant Professor at the University of Engineering and Technology (UET), Taxila, Pakistan where he is supervising several postgraduate students and heading the MAP (Microwave Antennas and Propagation) research group. His research interests include antennas, angle-of-arrival based channel modeling, microwave periodic structures and metamaterials.

Muhammad Farhan SHAFIQUE received the B.Eng. degree from Hamdard University, Karachi, Pakistan, in 2003, M.S. degree from the University of Paris East Marne-La-Vallée, Paris, France, in 2005 and PhD in Electronic and Communications Engineering from the University of Leeds, Leeds, UK in 2010. His research interests involve multilayer microwave device fabrication on LTCC technology, electromagnetic modeling of microwave structures, RF antenna, filters and MEMS packaging. He is also involved in dielectric characterization of materials using microwave techniques and fabrication of ceramic microfluidic devices. He is working as an Associate Director at the Center for Advanced Studies in Telecommunications (CAST) where he has established the MCAD (Microwave Components and Devices) research group. He has also setup a wide range of research facilities in the area of RF engineering which involves 4 state-of-the art laboratories. He is a reviewer of various journals and also a Senior Member of IEEE.

Sabih ur REHMAN is a Lecturer in Computing with the School of Computing and Mathematics at Charles Sturt University, Australia. Sabih has completed his $\mathrm{PhD}$ in the area of vehicular ad-hoc networks for which he was the recipient of competitive scholarship from Charles Sturt University. Sabih obtained his Bachelor degree from the University of South Australia, Adelaide in Electronics \& Telecommunication Engineering with Honours. Sabih's research expertise lies in the areas of Quality of Service (QoS), Cross-layer Protocol Architecture Designing, Wireless Propagation and Antenna Modeling using mathematical/stochastic models and conducting performance analysis. Sabih's current research is focused on the emerging area of Internet of Things (IoT) especially in context of Intelligent Transport Systems and Precision Agriculture. 